\title{
PENGARUH TRANSVERSE FRICTION TERHADAP SKALA NYERI PADA KASUS TENNIS ELBOW DI RSU SEMBIRING DELI TUA
}

\author{
Rudianto, Simson Sinuhaji \\ Program Studi Fisioterapi \\ Fakultas Keperawatan dan Fisioterapi Institut Kesehatan Medistra \\ Lubuk Pakam \\ Email: rudiantofisioterapist@gmail.com
}

\begin{abstract}
Data were obtained from Sembiring Deli Tua Hospital in Medan indicates that the number of patients with tennis elbow in January - June 2015 as many as 30 people suffering from tennis elbow on the elbow as a result of uncontrolled movement that lead to pain in the elbow area. The purpose of this study was to determine the effect of the transverse friction due to tennis elbow pain scale of the Elisabeth Hospital in Medan. This type of research is descriptive with the entire patient population that numbered 30 people tennis elbow, samples 23 people, the received data is primary data obtained directly from the respondents. Data were analyzed descriptively by looking at the percentage of the collected data. From the result of this study showed that in the entire sample frequency distribution of respondents by sex that many have tennis elbow is the female gender with a number of 15 people $(65.2 \%)$, while the distribution of the samples by age that many have tennis elbow is the age of 30-35 years old (43.5\%), while the distribution of the samples based on the job that many have tennis elbow is a housewife with a number of 10 people (43.5\%). Based on this study it can be concluded that there is the influence of transverse friction in patients with tennis elbow.
\end{abstract}

Key words : Transverse friction in tennis elbow

\section{PENDAHULUAN}

\section{A. Latar Belakang}

Nyeri siku merupakan salah satu kondisi muskuloskeletal yang sering dijumpai dalam kehidupan sehari-hari dan dapat menghambat seseorang dalam melakukan aktifitas. Gangguan nyeri siku ini bermacam-macam di antaranya epicondylitis lateralis (Tennis elbow), epicondylitis medialis (golfer elbow), arthritis traumatis, corpus liberum, tendinitis otot bicipitalis brachii dan bursitis olecrani (Aras, 2006).

Tennis elbow adalah penyakit degenerasi tendon yang paling sering mengenai siku. Kelainan ini menyebabkan rasa nyeri pada sisi lateral siku khususnya pada epicondylus lateralis dan otot ekstensor pergelangan tangan. Kelainan ini terutama terjadi pada pemain olah raga tennis lapangan atau pada mereka yang mempergunakan lengan bawah pada posisi pronasi secara berulang-ulang seperti pada ibu rumah tangga, pekerjaan tukang, pekerjaan salon, montir, pemahat dan lain-lain nya yg mempergunakan pergelangan tangan secara berulang-ulang dalam posisi ekstensiwrist .

Tennis elbow disebabkan oleh pembebanan yang berlebihan pada otototot ekstensor wrist serta suatu trauma langsung. Penyakit ini ditandai dengan adanya keluhan rasa sakit disiku bagian lateral epicondylus lateralis. Dimana terjadi robekan inkomplit pada origo teno periosteal dan otot ekstensor carpi radialis brevis di epicondylus lateralis humeri. Nyeri akan bertambah setelah beraktifitas, terutama pada gerakan dorso fleksi sendi pergelangan tangan, terasa kaku dan nyeri jika sendi siku diluruskan di pagi hari (Suharto, 2000).

Fisioterapis sebagai salah satu pelaksana pelayanan kesehatan ikut berperan dan bertanggungjawab dalam peningkatan derajat kesehatan, terutama yang berkaitan dengan obyek disiplin ilmunya yaitu gerak dan fungsi. Usaha untuk meningkatkan kesehatan oleh fisioterapi meliputi semua unsur yang terkait dalam upaya peningkatan 
derajat kesehatan yaitu peningkatan (promotif), pencegahan (preventif), penyembuhan (kuratif) dan pemeliharaan (rehabilitatif) sehingga dapat terwujud Indonesia sehat 2010 (WCPT, 1999, dikutip oleh Hargiani, 2001).

Tennis elbow merupakan cedera yang terjadi di epicondylus lateral akibat penggunaan otot-otot ekstensor yang berlebihan (overuse) sehingga terjadi peradangan (inflamasi) pada tendon ekstensor carpi radialis brevis. Prevalensi atau angka kejadian yang ada didunia, tennis elbow dialami1-3\% pada populasi umum, 6-15\% pada pekerja industri, $19 \%$ pada usia $30-50$ tahun lebih dominan wanita, $35-42 \%$ pada pemain tennis, 2-23\% pada pekerja umum seperti ibu rumah tangga, aktifitas dengan komputer, pemahat dan mengangkat beban berat (Sugijanto and Partono, Muki. 2006).

$\mathrm{Di}$ Indonesia umumnya penderita tennis elbow terjadi pada usia 25-55 tahun dengan gejala-gejala nyeri pada bagian lateral sendi siku terutama saat jari-jari tangan memegang atau meremas dengan kuat, pada usia dibawah 25 tahun dan usia lansia atau diatas 60 tahun jarang terjadi. Diperkirakan $65 \%$ dari seluruh penderita tennis elbow disandang oleh pemain tenis pemula, sedangkan $35 \%$ diderita oleh berbagai profesi dan pekerjaan seperti ibu rumah tangga yang baru pertama kali melakukan pekerjaan tersebut, dan profesi pemula atau pekerja pemula untuk melakukan pekerjaan tersebut (Wibowo, 2010).

Masalah yang ditimbulkan akibat tennis elbow ini yaitu adanya nyeri ketika melakukan gerakan dorso fleksi, back hand atau gerakan lainnya yang menyerupai pukulan back hand, nyeri yang dirasakan pada siku bagian belakang luar dan lengan bawah bagian luar dan menjalar ke pergelangan tangan dan mengakibatkan nyeri ketika beristirahat, adanya keterbatasan luas gerak sendi wrist karena adanya nyeri. Pada penderita yang mengalami kondisi tennis elbow sering mengalami kesulitan dalam melaksanakan aktifitas fungsional dasar seperti mencuci, memeras, menjemur kain, memutar baut, mengecat, membersihkan kebun, mengepal dan bermain tennis (Sugiri, 2007).

Jumlah pasien yang menderita tennis elbow di ruangan Fisioterapi RSU Sembiring Deli Tua dari tahun 2010 sampai 2014 tercatat sebanyak 256 orang pasien. Namun terhitung dari bulan September sampai Desember 2014sebanyak 30 orang pasien yang mengalami cedera pada siku akibat gerakan yang tidak terkontrol yang mengakibatkan nyeri pada daerah siku(Rekam Medik RSU Sembiring, 2015).

Berdasarkan dari data diatas maka peneliti terarik untuk meneliti Pengaruhu transverse frictionterhadap skala nyeri pada kasus tennis elbow, sehingga dengan pemberian tindakan fisioterapi tersebut diharapkan dapat menghilangkan keluhan penderita yaitu rasa nyeri. Tujuan penelitian ini adalah untuk mengetahui pengaruh transverse friction setelah pemakaian IR (Infra merah) dan TENS (Trancutaneus Electrical Nerve Stimulation) terhadap skala nyeri akibat tennis elbow di RSU Sembiring Deli Tua.

\section{METODE PENELITIAN}

Penelitian ini merupakan penelitian quasi eksperimen dengan deain one group pre dan post test. Dalam penelitian ini observasi dan pengukuran dilakukan sebelum dan sesudah perlakuan untuk melihat pengaruh transverse friction terhadap skala nyeri pada kasus tennis elbow. Penelitian dilakukan di RSU Sembiring Deli Tua pada Unit Rehabilitasi Medik Fisioterapi yang dilaksanakan pada bulan Januari-April 2015. Populasi penelitian ini adalah seluruh pasien rawat jalan dengan gejala dan tandatanda tennis elbow, yang sesuai dengan 
kriteria inklusi yang datang di RSU Sembiring Deli Tua Unit Rehabilitasi Medik ruang Fisioterapi. Sampel pada penelitian ini sebanyak 23 orang yang diambil dengan menggunakan teknik purposive sampling. Pengumpulan data primer dilakukan dengan menggunakan lembar observasi sebelum dan sesudah dilakukan intervensi sedangkan pengumpulan terhadap data sekunder diperoleh dari catatan rekam medis di RSU Sembiring Deli Tua, dan literaturliteratur yang mendukung. Analisis data univariat dilakukan untuk mendeskripsikan dan menjelaskan karakteristik masing-masing variabel dan disajikan dalam bentuk tabel distribusi frekuensi sedangkan analisis data bivariat dilakukan dengan menggunkan uji paired sample t-test dengan menggunakan tingkat kepercayaan $95 \%$ dengan $a=5 \%$. Jika $p \leq a=0,05$ maka hipotesa alternative diterima hipotesis nol ditolak, sehingga ada perbedaan nyeri akibat tennis elbow sebelum dan sesudah dilakukan manual Transverse friction di RSU Sembiring Deli Tua

\section{HASIL}

\section{A. Karakteristik Responden}

Karakteristik responden yang diamati meliputi umur, jenis kelamin dan pekerjaan. Hasilnya disajikan pada tabel berikut ini.

Tabel 1.

Karakteristik Responden Berdasarkan Umur

\begin{tabular}{ccrr}
\hline No & Umur & f & \multicolumn{1}{c}{$\%$} \\
\hline 1. & $30-35$ & 10 & 43,5 \\
2. & $36-40$ & 5 & 21,7 \\
3. & $41-45$ & 8 & 34,8 \\
\hline & Total & $\mathbf{2 3}$ & $\mathbf{1 0 0 , 0}$ \\
\hline
\end{tabular}

Tabel 1 di atas menunjukkan mayoritas responden berada pada kategori umur 30-35 tahun yaitu sebanyak 10 orang $(43,5 \%)$.
Tabel 2

Karakteristik Responden Berdasarkan Jenis Kelamin

\begin{tabular}{rlrr}
\hline No & $\begin{array}{c}\text { Jenis } \\
\text { Kelamin }\end{array}$ & f & \% \\
\hline 1. & Laki-laki & 8 & 34,8 \\
2. & Perempuan & 15 & 65,2 \\
\hline & Total & $\mathbf{2 3}$ & $\mathbf{1 0 0 , 0}$ \\
\hline
\end{tabular}

Tabel 2 di atas menunjukkan mayoritas responden berjenis kelamin perempuan sebanyak 15 orang $(65,2 \%)$.

Tabel 3.

Karakteristik Responden Berdasarkan Pekerjaan

\begin{tabular}{|c|c|c|c|}
\hline No & Pekerjaan & $\mathbf{f}$ & $\%$ \\
\hline 1. & IRT & 10 & \\
\hline 2. & PNS & 5 & 43,5 \\
\hline \multirow[t]{2}{*}{3.} & Karyawan & 8 & 21,9 \\
\hline & swasta & & \\
\hline
\end{tabular}

Tabel 3 di atas menunjukkan mayoritas responden memiliki pekerjaan sebagai IRT yaitu sebanyak 10 orang $(43,5 \%)$

\section{B. Skala Nyeri Sebelum dan Sesudah Dilakukan Intervensi Transverse Friction}

Gambaran Skala Nyeri Sebelum dan Sesudah Dilakukan Intervensi Transverse Friction disajikan pada tabel berikut ini.

Tabel 4.

Distribusi Skala Nyeri Sebelum Dilakukan Intervensi Transverse Friction

\begin{tabular}{|c|c|c|c|c|}
\hline $\begin{array}{l}\text { Skala } \\
\text { Nyeri }\end{array}$ & $f$ & $\%$ & Mean & SD \\
\hline 5 & 4 & 17,4 & 6,17 & 0,717 \\
\hline 6 & 11 & 47,8 & & \\
\hline 7 & 8 & 34,8 & & \\
\hline Total & 23 & 100 & & \\
\hline
\end{tabular}

bahwa sebelum dilakukan transverse friction mayoritas responden memiliki skala nyeri pada level 6 yaitu sebanyak 
11 orang $(47,8 \%)$ dengan nilai mean 6,17 dan $\mathrm{SD}=0,717$

Tabel 5

Distribusi Skala Nyeri Sesudah Dilakukan Intervensi Transverse Friction

\begin{tabular}{ccccc}
\hline $\begin{array}{c}\text { Skala } \\
\text { Nyeri }\end{array}$ & $\mathbf{f}$ & $\mathbf{\%}$ & Mean & SD \\
\hline 1 & 11 & 47,8 & 1,43 & 0,507 \\
2 & 12 & 52,2 & & \\
\hline Total & $\mathbf{2 3}$ & $\mathbf{1 0 0}$ & & \\
\hline
\end{tabular}

Tabel 5 di atas menunjukkan bahwa sesudah dilakukan transverse friction mayoritas responden memiliki skala nyeri pada level 2 yaitu sebanyak 12 orang $(52,2 \%)$ dengan nilai mean 1,43 dan $\mathrm{SD}=0,507$

\section{Pengaruh Transverse Friction Terhadap Skala Nyeri Pada Kasus Tennis Elbow}

Hasil analisis Pengaruh Transverse Friction Terhadap Skala Nyeri Pada Kasus Tennis Elbow disajikan pada tabel berikut ini:

Tabel 6.

Pengaruh Transverse Friction Terhadap Skala Nyeri Pada Kasus Tennis Elbow

\begin{tabular}{llllll}
\hline $\begin{array}{l}\text { Skala } \\
\text { Nyeri }\end{array}$ & Mean & SD & SE & t & sig \\
\hline $\begin{array}{l}\text { Sebelum } \\
\text { dan }\end{array}$ & & & & & \\
$\begin{array}{l}\text { sesudah } \\
\text { intervensi }\end{array}$ & 4,739 & 0,541 & 0,1134 & 2,0250 & 0,000 \\
\hline
\end{tabular}

Tabel 6 di atas menunjukkan bahwa berdasarkan hasil analisis dengan menggunakan uji paired sample t-test diperoleh nilai $p=0,000<$ alpha $=0,05$ yang berarti hipotesis alternatif diterima sehingga dapat disimpulkan bahwa terdapat pengaruh pemberian transverse friction terhadap penurunan skala nyeri.

\section{PEMBAHASAN}

\section{A. Karakteristik Responden}

Diperoleh karakteristik responden berdasarkan jenis kelamin, yang memiliki frekuansi tertinggi adalahjenis kelamin perempuan sebanyak 15 orang
$(65,2 \%)$.Berdasarkan karateristik umur, yang memiliki frekuensi tertinggi adalah usia 30-35 tahun sebanyak 10 orang (43,5\%).Berdasarkan karakteristik pekerjaan, yang memiliki frekuensi tertinggi adalah pekerjaan ibu rumah tangga (IRT) sebanyak 10 orang $(43,5 \%)$

Sering kali penderita Tennis elbow berusia 35 tahun hingga 55 tahun. Pada lansia berusia lebih dari 60 tahun atau usia dibawah 30 tahun jarang mengalami kondisi tersebut (Levesque, 2009).Karakteriatik berdasar jenis kelamin dalam penelitian ini perempuan lebih banyak mengalami tenis elbow dibanding laki laki karena perempuan melakukan aktifitas lebih besar dari laki laki.pada Pada Prevalensi atau angka kejadian yang ada didunia, tennis elbow dialami1-3\% pada populasi umum, 6$15 \%$ pada pekerja industri, $19 \%$ pada usia 30-50 tahun lebih dominan wanita,35-42\% pada pemain tennis, 2$23 \%$ pada pekerja umum seperti ibu rumah tangga, aktifitas dengan komputer, pemahat dan mengangkat beban berat (Leclerc et al, 2013).

Peneliti berasumsi usia mempengaruhi terjadinya Tenis elbow dan ibu rumah tangga lebih banyak yang mengalami Tennis elbowkarena aktifitas dari ibu rumah tangga lebih banyak menggunakan tangan seperti mencuci dan memeras kain, memuntir, menyapu dan lain-lain.

\section{B. Skala Nyeri Pada Tennis Sebelum Pemberian Transverse Friction di RSU Sembiring Deli Tua}

Diperoleh nilai skala nyeri sebelum intervensi nilai VAS5 sebanyak 4 orang $(17,4 \%)$, nilai VAS 6 sebanyak 11 orang $(47,8 \%)$ dan nilai VAS7 sebanyak 8 orang $(34,8 \%)$ dengan nilai Mean sebelum intervensi sebesar 6,17 dengan nilai SD sebesar 0,717 


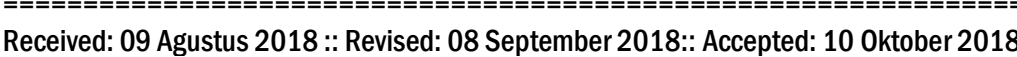

\section{Skala Nyeri Pada Tennis Sesudah Pemberian Transverse Friction di RSU Sembiring Deli Tua \\ Berdasarkan distribusi frekuensi} sesudah intervensi maka diperoleh skala nyeri dengan nilai VAS 1 sebanyak 11 orang $(47,8 \%)$ dan dengan nilai VAS 2sebanyak 12 orang( $52,2 \%$ ) dan nilai Mean sebesar 1,43 dan nilai SD sebesar 0,507 . Transverse friction merupakan suatu tehnik manipulasi yang bertujuan untuk melepaskan perlengketan, memperbaiki sirkulasi darah, dan menurunkan rasa nyeri secara langsung, Tehnik ini dilakukan penekanan pada satu titik tertentu pada jaringan target terapi dengan melintang dengan menggunakan ibu jari, ujung jari telunjuk secara lembut, kecil dan hanya pada titik yang menjadi target terapi dan tetap memelihara kontak dengan kulit. Asumsi peneliti adalah dengan pemberian Transverse friction penyebaran zat metabolik dikontrol dan dihambat sehingga rasa nyeri dapat berkurang, Transverse friction yang diberikan juga melepaskan endorphin sehingga menimbulkan efek counter irritation serta mengakibatkan penghambatan produksi neuro transmitter dengan demikian penghantaran rasa nyeri pada tingkat pusat yang lebih tinggi intensitasnya dikurangi.

\section{Pengaruh Pemberian Transverse Friction Terhadap Rerata Nyeri Pada Tennis Elbow di RSU Sembiring Deli Tua}

Dengan menggunakan paired sample t-test diperoleh hasil pengukuran sebelum dan sesudah Transverse friction terhadap skala nyeri pada kasus Tennis elbow diperoleh nilai $p=0,000<$ alpha $=0,05$ ternyata di peroleh pengaruh yang signifikan pemberian Tranverse friction pada Tennis elbow terhadap pengurangan nyeri.Transverse friction dapat memperbaiki keadaan otot dan tendon menjadi normal, mengurangi dan menghilangkan jaringan fibrous pada serabut otot atau tendon dan mempercepat proses penyerapan cairan. Dengan pemberian gerakan transversal terhadap struktur collagen saat intervensi Transverse friction maka akan mencegah terjadinya perlengketan jaringan dam dengan pemberian deep friction pada jaringan otot, tendon serta jaringan lunak lainnya dapat melepaskan atau mencerai-beraikan perlengketan jaringan yang terbentuk pada serabut otot atau tendon. (Wilson, 2001).

\section{KESIMPULAN}

Berdasarkan hasil penelitian dan pembahasan yang telah dilakukan, maka peneliti mengambil kesimpulan bahwa pemberian Transverse frictiondimana saat melakukan uji hipotesis dengan menggunakan paired sample t-test diperoleh hasil $p$ value sebesar 0,000 ( $p<0,05)$ dengan demikian $\mathrm{Ha}$ diterima. Dengan pemberian Transverse friction ini maka dapat menjadi terapi dasar IR dan TENS yang sudah dilakukan selama ini sudah mengurangi nyeri, dan dengan penambahan transverse friction pengurangan nyeri lebih bermanfaat.

\section{SARAN}

1. Bagi Institusi

Diharapkan Transverse frictiondapat ditambahkan setelah pemberian modalitas fisioterapi sehingga memudahkan mahasiswa dalam menangani pasien Tenis elbow.

\section{Bagi Rumah Sakit}

Diharapkan dapat menjadi prosedur tetap dalam pemberian tindakan terapi pada pasien tennis elbow khususnya dalam mengurangi rasa nyeri. Bagi Rumah Sakit

\section{Bagi Peneliti Selanjutnya}

Hendaknya peneliti berikutnya menggunakan jumlah sampel yang lebih besar dari penelitian ini dan waktu penelitian yang lebih lama dari penelitian ini agar hasil yang 
didapat maksimal.

\section{Bagi Profesi Fisioterapi}

Dapat di jadikan bahan acuan pembuatan SOP (Standar Operasional Prosedur) penanganan tennis elbow.

\section{Bagi Pasien}

Agar pasien paham tentang indikasi Transverse friction dan dapat menerima sebagai tindakan terapi dalam penanganan fisioterapi.

\section{DAFTAR PUSTAKA}

Aras, Djohan, "Manual Terapi pada Tennis Elbow", Makalah ini disampaikan pada TITAFI XII, Ujungpandang,1996. Diakses tanggal 20 Maret 2015

Arikunto, Suharsimi 2013"Prosedur Penelitian : Suatu pendekatan Praktik" Jakarta : Rineka Cipta.

Cyriax, James, "Textbook Of Orthopaedic Medicine", Ninth Edition, Baillrere Tindall, London, 2007.

Dorland, W.A. Newman. 2002. Kamus Kedokteran Dorland, alih bahasa Huriwati Hartanto, dkk., edisi 29. EGC, Jakarta.

Durall, C. 2011. Adhesiva Capsulitis. In: Brotzman, S.B., Manke, R.C., editors. Clinical Orthopedic Rehabilitation : an evidence - based.Second edition.Philadelphia : Elsevier.

Ehrlich, GE. 2003. Tennis Elbow. Bulletin of the World Health Organization ;81(9): 671-676.

Suharto. Fisioterapi pada Tennis Elbow tipe II. CDK. 2000; 129.

Taylor, M. P \& Taylor, K. D. (2007). Mencegah Dan Mengatasi Cedera Olahraga. PT Rajagrafindo Persada. Jakarta

Wibowo Hardianto, Buku Kedokteran, EGC, Jakarta, 2010.

Wilson, Jacob. 2001. "Superficial Muscles of the Back Part II". Available at http://www.abcbodybuilding.com. 